\title{
The efficacy of different bandaging methods in patients with breast cancer-related lymphedema: A prospective, randomized study
}

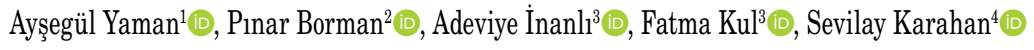 \\ ${ }^{1}$ Department of Physical Medicine and Rehabilitation, Gülhane Training and Research Hospital, Ankara, Turkey \\ ${ }^{2}$ Department of Physical Medicine and Rehabilitation, Ankara City Hospital, Ankara, Turkey \\ ${ }^{3}$ Department of Physical Medicine and Rehabilitation, University of Hacettepe Faculty of Medicine, Ankara, Turkey \\ ${ }^{4}$ Department of Biostatistics, University of Hacettepe Faculty of Medicine, Ankara, Turkey
}

Received: March 27, 2020 Accepted: June 17, 2020 Published online: May 25, 2021

\begin{abstract}
Objectives: The aim of this study was to evaluate the comparative efficacy of $3 \mathrm{M}^{\mathrm{m} w}$ Coban ${ }^{\mathrm{nt}} 2$ layer system and conventional multi-layer short-stretch bandaging in terms of volume reduction, ultrasonographic measurements, functional status, and quality of life (QoL) in the treatment of patients with breast cancer-related lymphedema (BCRL).

Patients and methods: This prospective, single-blind, randomized study included a total of 60 BCRL patients (60 females; mean age $54.9 \pm 9.6$ years; range, 30 to 73 years). The patients were randomly allocated to Group $1(n=30)$ and Group 2 ( $n=30)$. Both groups received complex decongestive therapy (CDT) including skin care, lymphedema exercises, and manual lymphatic drainage (MLD) combined with traditional multi-layer short-stretch bandaging five times per week for three weeks in Group 1 and with $3 \mathrm{M}^{\mathrm{ma}}$ Coban 2 layer system bandaging two times per week for three weeks in Group 2. Differences in volumes, excess volumes, ultrasonographic measurements, QoL, and functional assessment scores were evaluated at baseline, after three weeks of intensive treatment period, and at two months of follow-up. Functional status was evaluated by the Quick Disability of Arm Shoulder and Hand Questionnaire (Q-DASH), while the QoL was assessed using the Turkish version of Lymphedema Quality of Life Questionnaire-Arm (LYMQOL-Arm). The duration and easiness of applying bandages by physiotherapists and comfortableness of bandages according to patients and physiotherapists were also evaluated using a questionnaire.
\end{abstract}

Results: The demographic and clinical properties were similar between the groups. There were significant improvements in the volumes, excess volumes, ultrasonographic measures, functional scores, and QoL scores in both groups at the end of treatment. The improvements were sustained at two months of follow-up.

Conclusion: The $3 \mathrm{M}^{\mathrm{Tw}}$ Coban $^{\mathrm{Tw}} 2$ layer bandaging as a part of CDT twice a week for a period of three weeks can significantly reduce the volume and improve the disability and impaired QoL, similar to conventional short-stretch multi-layer bandages. In addition, treatment with this layer system enables a time-efficient, easy, and comfortable application of bandaging with increased mobility of the upper extremity.

Keywords: Bandaging, function, lymphedema treatment, quality of life, ultrasonography.

Upper extremity lymphedema is a concerning complication after treatment for breast cancer. If left untreated, functional disability, psychosocial problems, and impaired quality of life (QoL) can be seen in patients with breast cancer-related lymphedema $(\mathrm{BCRL}){ }^{[1-3]}$
Complex decongestive therapy (CDT) is the most popular and gold standard treatment for patients with lymphedema and comprises two phases. Phase 1 therapy includes education and skin care, manual lymphatic drainage (MLD), multi-layer non-elastic compression bandaging

Corresponding author: Ayşegül Yaman, MD. Gülhane Eğitim ve Araştırma Hastanesi Fizik Tedavi ve Rehabilitasyon Kliniği, 06010 Keçiören, Ankara, Türkiye.

e-mail: aysegulyaman06@gmail.com

Cite this article as:

Yaman A, Borman P, İnanlı A, Kul F, Karahan S. The efficacy of different bandaging methods in patients with breast cancer-related lymphedema: A prospective, randomized study. Turk J Phys Med Rehab 2021;67(2):155-166.

Presented at the $7^{\text {hi }}$ International Lymphedema Framework Conference, June, 22-24, 2017, Siracusa, Italy. 
and exercises, while phase 2 therapy comprises skin care and exercise in addition to self-massage and pressure garments. ${ }^{[4,5]}$ Compression of the extremity by bandaging is essential in the treatment of lymphedema. ${ }^{[6-8]}$ Compression in the intensive phase of CDT is not standardized, but generally is performed by multi-layer short-stretch bandages. The application of these conventional bandages may be time-consuming due to the multi-layer nature and short daily intervals. It may also restrict the function of the upper extremity due to the coarse and bulky contexture of the bandages. ${ }^{[8]}$

A relatively new bandaging system, $3 \mathrm{M}^{\mathrm{pm}}$ Coban $^{\text {tw }} 2$ layer compression system (3M Healthcare, $\mathrm{MN}, \mathrm{USA}$ ), is designed to deliver sustained therapeutic compression to improve comfort, mobility, and QoL for lymphedema patients. It is a disposable, singleuse system that eliminates time and expense of washing and re-rolling bandages, while minimizing the risk associated with potential contamination. It can be performed by three- to four-day-intervals. ${ }^{[9,10]}$ The materials used in the two thin layers of the system are safe for skin and were developed with unique stretch and cohesion properties to provide the ideal compression and help patients to overcome the challenges of wearing bandages during intensive therapy. ${ }^{[1,12]}$ There are some previous reports indicating the effectiveness of these Coban ${ }^{\text {max }}$ bandages, but the included outcome measures, duration of effectiveness, and number of study-groups may not be convincing in the literature. ${ }^{[9-11]}$

In the present study, we aimed to evaluate the comparative efficacy of the $3 \mathrm{M}^{\mathrm{mi}}$ Coban $^{\mathrm{Tx}} 2$ layer bandaging and conventional multi-layer short-stretch bandaging in phase 1 CDT of BCRL patients in terms of volume reduction, ultrasonographic measurements, functional status, and QoL in both short- and long-term.

\section{PATIENTS AND METHODS}

This prospective, single-blind, randomized study was conducted at Hacettepe University Medical School Department of Physical Medicine and Rehabilitation between September 2015 and December 2016. A total of 200 BCRL patients who were referred to lymphedema unit were evaluated according to the eligibility criteria. Inclusion criteria were as follows: age between 18 and 65 years; having unilateral breast cancer surgery; having volume difference between the affected and unaffected upper extremities of 20 to $40 \%$ (Stage 2 lymphedema); having completed chemotherapy and/or radiation therapy; being compliant and fully attended to the intensive CDT sessions including skin care, MLD, bandaging (conventional or Coban ${ }^{\text {tw }} 2$ layer) and lymphedema exercises for three weeks, and follow-up at two months. Exclusion criteria were as follows: having edema before breast cancer treatment; having a history of contralateral breast cancer; medical history comprising other causes of lymphedema; having recurrence or metastasis of breast cancer; having a contraindication for CDT (i.e., renal insufficiency, congestive heart failure, infection, thrombosis, thyroid or abdominal disease, or severe vascular disease); having prior therapy for lymphedema; not being compliant to self-massage and pressure garments in the second phase of CDT. Of all patients, 77 were found to be eligible for the study. However, 11 patients did not agree to take part in the study due to different reasons (i.e., transportation difficulties, not being able to afford the costs of bandages and/or pressure garments, or time inconvenience), one patient developed a carcinoma in the opposite breast, three patients did not comply to the components of the second phase of CDT (incompliance to self-MLD, exercises and/or pressure garments), and two patients did not attend to the second-month follow-up visit.

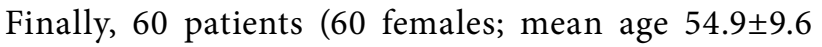
years; range, 30 to 73 years) were included in the study. The study flow chart is shown in Figure 1. A written informed consent was obtained from each patient. The study protocol was approved by the Ethics Committee of Non-invasive Clinical Research of Hacettepe University Medical School (No. GO 15/128-09). The study was conducted in accordance with the principles of the Declaration of Helsinki.

Demographic and clinical characteristics of the patients including age, sex, body mass index (BMI), education status, marital status, occupation, regular exercise habit, hand dominancy, and lesion site were recorded. Breast cancer treatments, type of surgery, histopathological diagnosis, cancer stage, adjuvant treatments such as radiation therapy, chemotherapy, or hormonal therapy were noted in all patients. Lymphedema characteristics including duration of lymphedema, initial limb site (proximal, distal), positivity of Stemmer's sign were assessed. The severity of lymphedema is graded using the scale from the International Society of Lymphology (ISL). ${ }^{[13]}$

\section{Measurements}

The presence of lymphedema was assessed by inter-limb volume difference based on the serial 
circumferential measurements in both affected and non-affected extremities. The clinical diagnosis of BCRL was defined as an inter-limb difference of $>10 \%$ in volume or excess volume between the affected and non-affected limbs. ${ }^{[13,14]}$ The patients with a volume difference of 20 to $40 \%$ (Grade 2) were included in the study.

Circumferential measurements were performed by a standard $1-\mathrm{cm}$ retractable tape, starting at the level of ulnar styloid, at $4-\mathrm{cm}$ intervals along the arms and converted to an approximate arm volume by simplified truncated cone formula. ${ }^{[15,16]}$ The excess percentage limb volume was expressed in a percentage reduction in edema of the affected limb, which was calculated using standard methods. ${ }^{[16]}$ Excess limb volume represented the difference between both limbs and was expressed in $\mathrm{mL}$. Each patient was assessed by a single researcher who was blinded to the group allocation.
The ultrasonographic measurements included measurements of skin and subcutis/soft tissue thickness of the affected upper extremities. A 5 to $12-\mathrm{MHz}$ linear array probe (LOGIQ P5, GE Medical Systems, IL, USA) was used to obtain cross-sectional images of the skin and soft tissue thickness (subcutis) at three standardized points as follows: (i) elbow, the mid-point between the medial and lateral epicondyles; (ii) proximal, $10-\mathrm{cm}$ proximal to the elbow point along the line of the humerus and the bicipital groove between the mid-point of the medial and lateral epicondyles; and (iii) distal, 10-cm distal to the elbow point along the line of the radial and ulnar styloid processes between the mid-point of the medial and lateral epicondyles. ${ }^{[17,18]}$ All of the ultrasonographic measurements were performed by a single blinded researcher.

Functional disability of the affected extremity was evaluated by the Turkish version of the Quick

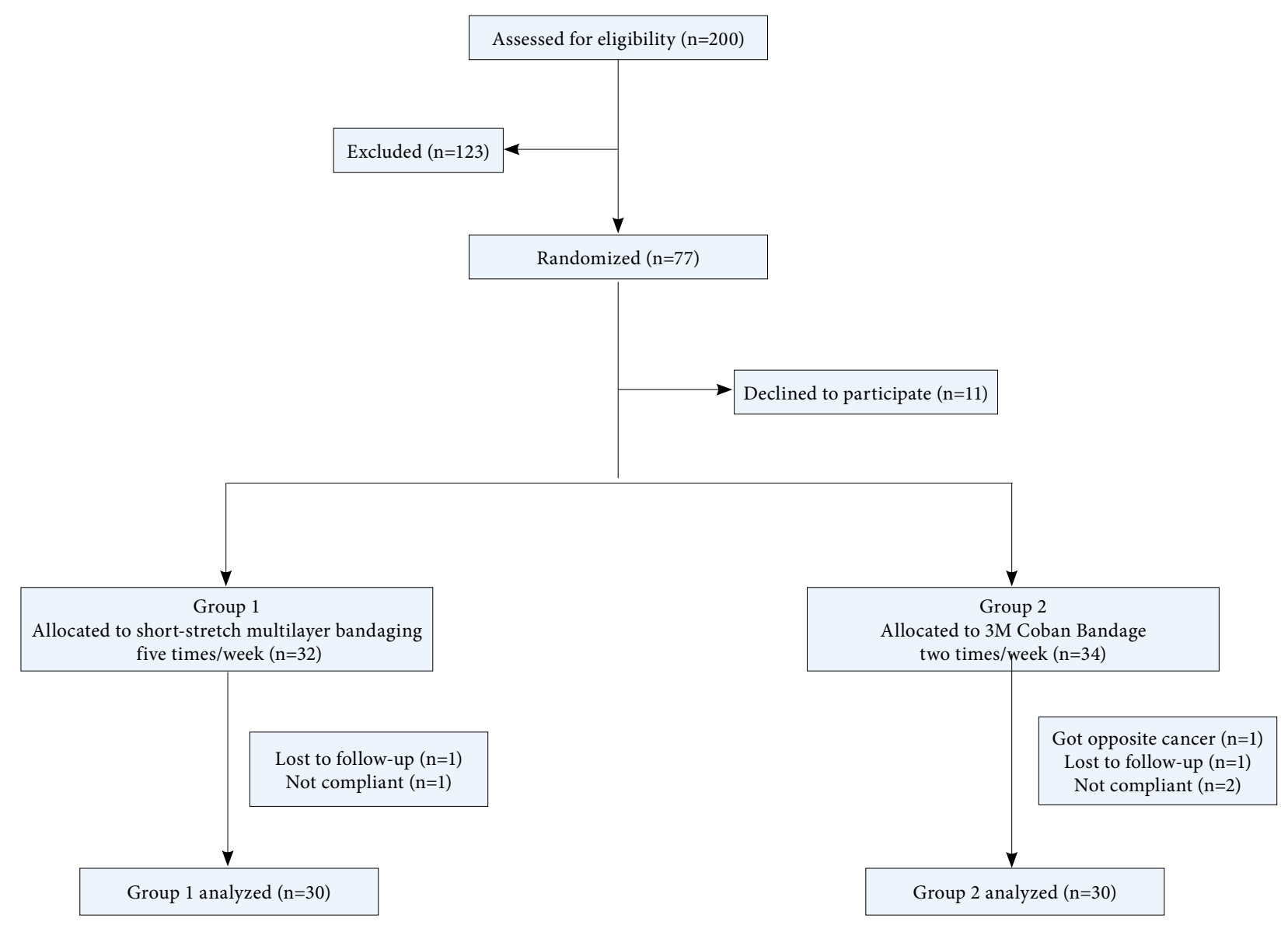

Figure 1. Study flowchart. 
Disability of Arm, Shoulder and Hand Questionnaire (Q-DASH) ${ }^{[19,20]}$ The QoL was assessed by the Turkish version of Lymphedema Quality of Life QuestionnaireArm (LYMQOL-Arm). ${ }^{[21]}$ It consists of four domains (function, appearance, symptoms, and mood) with 28 items. Each item receives a score between 1 and 4, and higher scores indicate a worse QoL. Also, there is an overall QoL rating which was scored between 0 and $10 .{ }^{[21,22]}$

\section{Randomization and assignment to groups}

Randomization was performed using the sealed envelope technique. All patients were randomly allocated to Group $1 \quad(n=30$, skin care, MLD, traditional multi-layer short-stretch bandaging five times per week and lymphedema exercises) or to Group $2\left(\mathrm{n}=30\right.$, skin care, MLD, and $3 \mathrm{M}^{\mathrm{mix}}$ Coban $^{\mathrm{mm}}$ 2 layer system two times per week for three weeks and lymphedema exercises).

\section{Interventions}

\section{Complex decongestive therapy}

All patients were educated for skin care and maintenance of healthy body weight and delivered a written brochure for general advices in the first visit by the same lymphedema therapist. The patients received MLD for a period of 45-min according to the Vodder technique $e^{[23,24]}$ by the same experienced and certified physiotherapist.
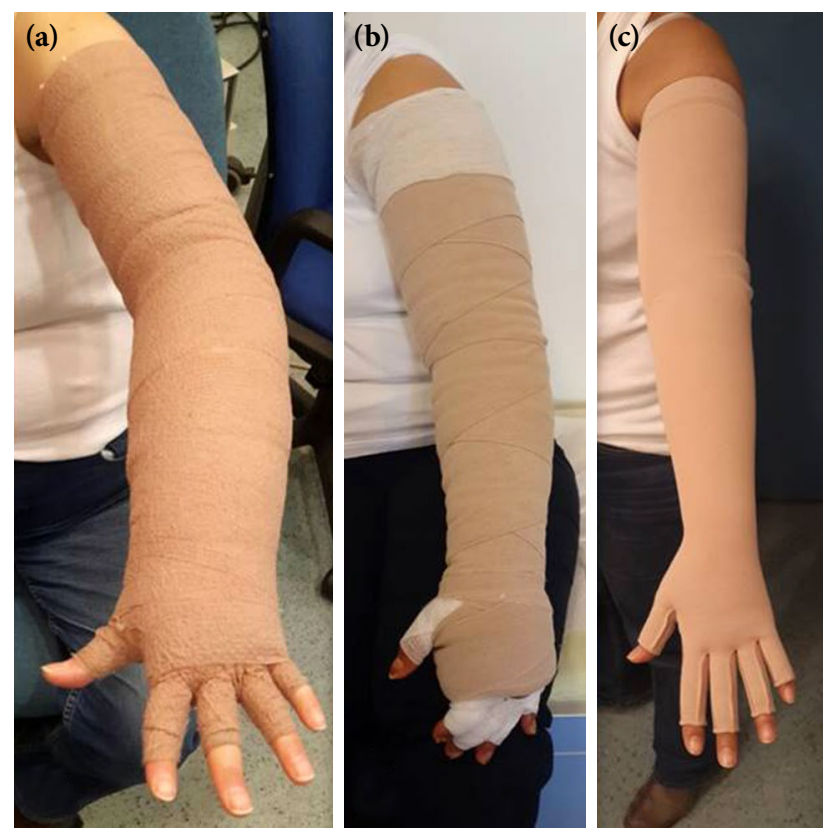

Figure 2. Images of patients with (a) Coban $^{\mathrm{TM}}$ bandage, (b) multi-layer conventional bandage, and (c) pressure garment.
After the MLD, Group 1 received non-elastic, short-stretch, multi-layer bandages which were applied and changed daily, except for weekends. Multi-layer compression bandages were applied such that the most compression was at the distal parts and the compression decreased gradually moving to proximal sites. ${ }^{[25]}$ Group 2 received Coban ${ }^{\text {Tu }} 2$ layer bandaging in which the first soft foam layer was applied directly to the skin without any tension and the second contracting and compressing layer was performed with full stretch. ${ }^{[26]}$ The conventional and Coban $^{\text {Tx }} 2$ layer bandages were applied by the same physiotherapists. The images of patients with different bandage types are shown in Figure 2. All patients received 20-min individualized active exercise program after bandaging under the supervision of the same experienced physiotherapists. The exercises included abdominal breathing exercise, neck and shoulder stretching, pumping and non-isometric strengthening of arm-muscles to facilitate lymphatic flow and improve strength and range of motion. ${ }^{[27]}$

\section{Maintenance phase}

After the intensive CDT period, all patients were prescribed pressure garments with CCL2 pressure and instructed to wear the garment daily (removed at night) and to perform self-MLD and self-exercises for $20 \mathrm{~min}$ at least three times per week and delivered printed materials for self-management. The compliance to the second phase ofCDT was measured with a questionnaire evaluating interval and duration of self-MLD and self-exercises, as well as duration of wearing pressure garments for all patients. ${ }^{[28]}$ The participants were asked to report how often they completed the self-care modalities (i.e., wearing pressure garment, self-MLD, and self-exercises) at the frequency recommended by the clinicians. Four adherence intervals were provided: less than $25 \%$ of the time (not very), 25 to $49 \%$ of the time (moderate), 50 to $74 \%$ of the time (high), and more than or equal to $75 \%$ of the time (extremely high).

\section{Outcome measures}

The primary outcome measures were defined as extremity excess volumes and percent changes of excess volumes. The secondary outcomes were improvement in QoL, functional status scores, and ultrasonographic measurements, which were evaluated at baseline, after three weeks of intensive treatment period, and at two months of follow-up in all patients.

The duration and easiness of applying the bandages by physiotherapists, and comfortableness 
of the bandages for the patients were also evaluated using a questionnaire which consisted of six questions with a rating scale of $0-10$ applied at the first and third weeks of treatment: 1-comfort of the bandage, 2 -ability to wear clothes, 3-ability to bend arm, 4-appearance, 5-easiness of application for patients, and 6 -overall view on product. The physiotherapists and patients replied applicable questions. The list of questions included in the survey was generated based on the published literature and consultation with experienced lymphedema specialists familiar to both types of bandages. ${ }^{[9,10,29]}$

\section{Statistical analysis}

The sample size was calculated using the $G^{\star}$ Power for Windows version 3.1.9.2 (Heinrich-Heine-Universität Düsseldorf, Düsseldorf, Germany) and was based on the change in lymphedema as indicated by volume. With an effect size of 0.81 , the statistical power and statistical level of significance for the study were set at 0.8 and 0.05 , respectively. The sample size for each group was determined as 25 with a power of $80 \%$ and $5 \%$ error margin.

Statistical analysis was performed using the IBM SPSS version 22.0 software (IBM Corp., Armonk, NY, USA). Descriptive data were presented in mean \pm standard deviation (SD) or median (min-max) for continuous variables or in number and percentage for categorical variables. The chi-square or Fisher's exact tests were used for the difference of categorical variables between the groups. The Kolmogorov-Smirnov and Levene's tests were used to indicate normal distribution and homogeneity of the variance, respectively. The differences between numerical variables of two independent groups were assessed by the independent samples t-test or MannWhitney $U$ test. The Wilcoxon test was carried out to assess differences between the patient and therapist evaluations before and after treatment. Repeated measurements of outcome variables were analyzed using the variance analysis. The pairwise comparisons were made using the Bonferroni test. A $p$ value of $<0.05$ was considered statistically significant.

\section{RESULTS}

Baseline demographic and clinical characteristics and lymphedema features of the patients are shown in Table 1. Most of the patients were overweight and the mean BMI was $31.22 \mathrm{~kg} / \mathrm{m}^{2}$. In both groups, the majority of the patients were married and housewives. Approximately half of the patients graduated from a high school or university. For breast cancer treatments, the most common type of surgery was modified radical mastectomy and the majority of the patients were treated with chemotherapy and radiation therapy. There was no statistically significant difference in demographic and clinical characteristics between the groups. Regarding lymphedema, $53.3 \%$ of the patients had their dominant side affected by lymphedema which was developed after a median of 11 months from surgery. The median duration of lymphedema was 24 months. All participants had Grade 2 lymphedema according to the ISL staging. The mean inter-limb volume difference among women with lymphedema was $28.26 \%$ at baseline.

The difference in volumes and excess volumes which were evaluated at baseline, after treatment, and two months after treatment is presented in Table 2 and Figure 3. At baseline evaluation, there were no significant differences between the study groups in terms of volumes and percentage excess volumes. When the volumetric measurements of affected extremities were compared between the patient groups for all times, there was no statistically significant difference $(\mathrm{p}>0.05)$. In terms of the percentage excess volumes, the improvements were similar between the groups.

The Q-DASH scores of the patients which indicate functional status of the upper limb, are shown in Table-2. The baseline scores of Q-DASH were similar between the groups. Both groups had improved functional scores at the end of treatment period, although there was a statistically significant improvement in Group 1.

The baseline QoL scores as assessed by the LYMQOL-Arm were statistically similar between the groups. There were significant improvements in all subgroups of the LYMQOL-Arm for both patient groups after treatment. The improvement sustained at two months of follow-up in both groups (Table 3 ).

The ultrasonographic measurements which were performed at baseline, after treatment, and at two months are shown in Table 4. The subcutaneous thickness scores in all prespecified time points and the proximal and distal limb skin thickness scores decreased after treatment in both groups and these improvements were sustained up to two months. 
According to the physiotherapists, there was no significant difference between the two groups in terms of the easiness of application. The duration of bandage application for the Coban ${ }^{\mathrm{Tm}} 2$ layer group was shorter than that for short-stretch bandaging group. The Coban ${ }^{\mathrm{Tx}}$ bandages were more comfortable and better in overall and in appearance than the conventional bandages. The scores of the

\section{TABLE 1}

Baseline demographic, clinical and lymphedema characteristics of patients

\begin{tabular}{|c|c|c|c|c|c|c|c|c|c|}
\hline & \multicolumn{4}{|c|}{ Group $1(\mathrm{n}=30)$} & \multicolumn{4}{|c|}{ Group $2(\mathrm{n}=30)$} & \multirow[b]{2}{*}{$p$} \\
\hline & $\mathrm{n}$ & $\%$ & Mean \pm SD & Median & $\mathrm{n}$ & $\%$ & Mean \pm SD & Median & \\
\hline Age (year) & & & $54.3 \pm 9.3$ & & & & $55.4 \pm 10$ & & 0.642 \\
\hline Body mass index $\left(\mathrm{kg} / \mathrm{m}^{2}\right)$ & & & $30.9 \pm 5.0$ & & & & $31.6 \pm 5.5$ & & 0.616 \\
\hline Education & & & & & & & & & 0.184 \\
\hline Illiterate & 0 & 0 & & & 0 & 0 & & & \\
\hline Primary school & 15 & 50 & & & 12 & 40 & & & \\
\hline High school & 10 & 33.3 & & & 7 & 23.3 & & & \\
\hline University & 5 & 16.7 & & & 11 & 36.7 & & & \\
\hline Marital status & & & & & & & & & 0.359 \\
\hline Married & 27 & 90 & & & 23 & 76.7 & & & \\
\hline Single & 2 & 6.7 & & & 4 & 13.3 & & & \\
\hline Widow & 1 & 3.3 & & & 3 & 10 & & & \\
\hline Occupation & & & & & & & & & 0.962 \\
\hline Housewife & 17 & 56.7 & & & 16 & 53.3 & & & \\
\hline Worker & 0 & 0 & & & 0 & 0 & & & \\
\hline Retired & 10 & 33.3 & & & 11 & 36.7 & & & \\
\hline Officer & 3 & 10 & & & 3 & 10 & & & \\
\hline Hand dominance & & & & & & & & & 1 \\
\hline Right & 29 & 96.7 & & & 28 & 93.3 & & & \\
\hline Left & 1 & 3.3 & & & 2 & 6.7 & & & \\
\hline Exercise habit & & & & & & & & & 0.552 \\
\hline Yes & 9 & 30 & & & 6 & 20 & & & \\
\hline No & 21 & 70 & & & 24 & 80 & & & \\
\hline Type of surgery & & & & & & & & & 0.424 \\
\hline Modified radical mastectomy & 28 & 93.3 & & & 25 & 83.3 & & & \\
\hline Lumpectomy & 2 & 6.7 & & & 5 & 16.7 & & & \\
\hline Breast cancer & & & & & & & & & 0.806 \\
\hline Stage 1 & 3 & 10 & & & 2 & 6.7 & & & \\
\hline Stage 2 & 18 & 60 & & & 17 & 56.7 & & & \\
\hline Stage 3 & 9 & 30 & & & 11 & 36.7 & & & \\
\hline Histopathologic diagnosis & & & & & & & & & 0.049 \\
\hline Infiltrative ductal & 25 & 83.3 & & & 20 & 66.7 & & & \\
\hline Infiltrative lobular & 2 & 6.7 & & & 6 & 20 & & & \\
\hline Mix (ductal + lobular) & 3 & 10 & & & 1 & 3.3 & & & \\
\hline Other & 0 & 0 & & & 3 & 10 & & & \\
\hline \multicolumn{10}{|l|}{ Adjuvant therapies } \\
\hline Chemotherapy positive & 28 & 93.3 & & & 27 & 90 & & & 1.000 \\
\hline Radiotherapy positive & 24 & 80 & & & 24 & 80 & & & 1.000 \\
\hline Hormonotherapy positive & 23 & 76.7 & & & 22 & 75.9 & & & 1.000 \\
\hline Duration of lymphedema (month) & & & $37.3+33.71$ & 36 & & & $34.2+36.3$ & 18 & 0.543 \\
\hline Dominant side involvement & 16 & 53.3 & & & 16 & 53.3 & & & 1.000 \\
\hline Stemmer sign & & & & & & & & & 0.188 \\
\hline Positive & 21 & 70 & & & 15 & 50 & & & \\
\hline Negative & 9 & 30 & & & 15 & 50 & & & \\
\hline
\end{tabular}




\begin{tabular}{|c|c|c|c|c|}
\hline Volum & ess volumes, and & $\begin{array}{l}\text { BLE } 2 \\
\text { SH scores at pr }\end{array}$ & ified time points & \\
\hline & Before treatment & After treatment & $2^{\text {nd }}$ month control & Intra-group \\
\hline & Mean \pm SD & Mean \pm SD & Mean \pm SD & $p$ \\
\hline Volumes $\left(\mathrm{cm}^{3}\right)$ & & & & $0.000^{\mathrm{a}}$ \\
\hline Group 1 & $3070 \pm 538$ & $2795 \pm 468.9$ & $2877 \pm 526.5$ & $0.000^{\mathrm{b}}$ \\
\hline Group 2 & $3139 \pm 715.1$ & $2900 \pm 623.5$ & $3056 \pm 712.3$ & $0.103^{c}$ \\
\hline$P$ value between groups & 0.673 & 0.465 & 0.273 & $0.000^{\mathrm{d}}$ \\
\hline & & & & $0.096^{\mathrm{e}}$ \\
\hline & & & & $0.000^{\mathrm{f}}$ \\
\hline Excess volume (\%) & & & & $0.000^{\mathrm{a}}$ \\
\hline Group 1 & $28 \pm 6.4$ & $17.0 \pm 6.1$ & $19.7 \pm 7.8$ & $0.000^{\mathrm{b}}$ \\
\hline Group 2 & $28.5 \pm 6.0$ & $18.6 \pm 6.0$ & $22.9 \pm 7.4$ & $0.045^{c}$ \\
\hline $\mathrm{P}$ value between groups & 0.748 & 0.301 & 0.110 & $0.000^{\mathrm{d}}$ \\
\hline & & & & $0.000^{\mathrm{e}}$ \\
\hline & & & & $0.001^{\mathrm{f}}$ \\
\hline Q-DASH & & & & $0.391^{\mathrm{a}}$ \\
\hline Group 1 & $48.0 \pm 21.7$ & $43.4 \pm 20.6$ & $39.9 \pm 18.9$ & $0.030^{\mathrm{b}}$ \\
\hline Group 2 & $45.5 \pm 19.5$ & $43.5 \pm 23.4$ & $40.3 \pm 21.7$ & $0.472^{c}$ \\
\hline $\mathrm{P}$ value between groups & 0.641 & 0.989 & 0.931 & $1^{\mathrm{d}}$ \\
\hline & & & & $0.289^{\mathrm{e}}$ \\
\hline & & & & $0.617^{\mathrm{f}}$ \\
\hline $\begin{array}{l}\text { SD: Standard deviation; Q-DASH } \\
\text { treatment and control for Group } \\
\text { for Group 2; f: After treatment an }\end{array}$ & $\begin{array}{l}\text { Disability-of-Arm-Shou } \\
\text { treatment and control } \\
\text { for Group } 2\end{array}$ & $\begin{array}{l}\text { 1-Hand Questionnai } \\
\text { 1; } \text { : Before and aft }\end{array}$ & $\begin{array}{l}\text { re and after treatment } \\
\text { nt for Group } 2 ; \text {; : Before }\end{array}$ & $\begin{array}{l}\text { roup 1; }{ }^{\text {b: Before }} \\
\text { ment and control }\end{array}$ \\
\hline
\end{tabular}

\begin{tabular}{|c|c|c|c|c|}
\hline \multicolumn{5}{|c|}{$\begin{array}{c}\text { TABLE } 3 \\
\text { Lymphedema Quality of Life-Arm scores }\end{array}$} \\
\hline & Before treatment & After treatment & $2^{\text {nd }}$ month control & Intra-group \\
\hline & Mean \pm SD & Mean \pm SD & Mean \pm SD & $p$ \\
\hline \multicolumn{5}{|l|}{ Function } \\
\hline Group 1 & $2.1 \pm 0.7$ & $1.6 \pm 0.7$ & $1.7 \pm 0.6$ & $0.000^{\mathrm{a}}$ \\
\hline Group 2 & $2.1 \pm 0.7$ & $1.7 \pm 0.5$ & $1.7 \pm 0.6$ & $0.000^{\mathrm{b}}$ \\
\hline$P$ value between groups & 0.906 & 0.253 & 0.313 & \\
\hline \multicolumn{5}{|l|}{ Appearance } \\
\hline Group 1 & $2.6 \pm 0.9$ & $1.8 \pm 0.7$ & $2.0 \pm 0.8$ & $0.000^{\mathrm{a}}$ \\
\hline Group 2 & $2.4 \pm 0.9$ & $1.8 \pm 0.6$ & $1.9 \pm 0.7$ & $0.000^{\mathrm{b}}$ \\
\hline $\mathrm{P}$ value between groups & 0.358 & 0.660 & 0.917 & \\
\hline \multicolumn{5}{|l|}{ Symptom } \\
\hline Group 1 & $2.2 \pm 0.8$ & $1.7 \pm 0.7$ & $1.8 \pm 0.6$ & $0.000^{\mathrm{a}}$ \\
\hline Group 2 & $2.3 \pm 0.7$ & $1.9 \pm 0.6$ & $1.9 \pm 0.6$ & $0.000^{\mathrm{b}}$ \\
\hline$P$ value between groups & 0.533 & 0.184 & 0.281 & \\
\hline \multicolumn{5}{|l|}{ Emotion } \\
\hline Group 1 & $2.0 \pm 0.7$ & $1.6 \pm 0.5$ & $1.6 \pm 0.5$ & $0.000^{\mathrm{a}}$ \\
\hline Group 2 & $2.2 \pm 0.8$ & $1.6 \pm 0.5$ & $1.8 \pm 0.7$ & $0.000^{\mathrm{b}}$ \\
\hline $\mathrm{P}$ value between groups & 0.229 & 0.917 & 0.341 & \\
\hline \multicolumn{5}{|l|}{ Overall } \\
\hline Group 1 & $5.7 \pm 2.0$ & $7.8 \pm 1.3$ & $7.3 \pm 1.6$ & $0.000^{\mathrm{a}}$ \\
\hline Group 2 & $5.0 \pm 2.2$ & $7.5 \pm 1.3$ & $6.6 \pm 1.8$ & $0.000^{\mathrm{b}}$ \\
\hline $\mathrm{P}$ value between groups & 0.187 & 0.386 & 0.141 & \\
\hline
\end{tabular}


(a)

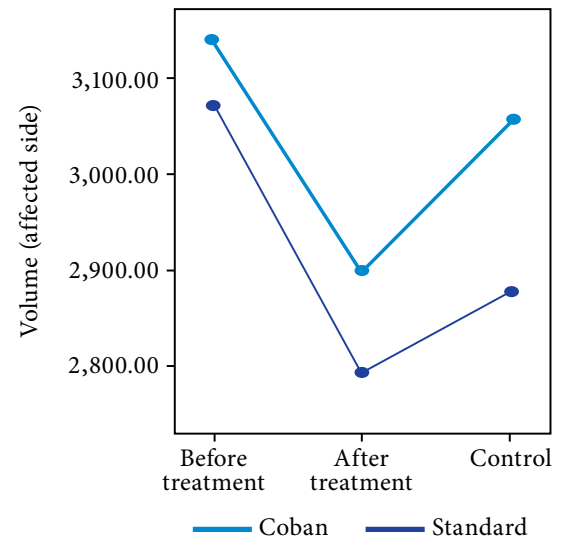

(b)

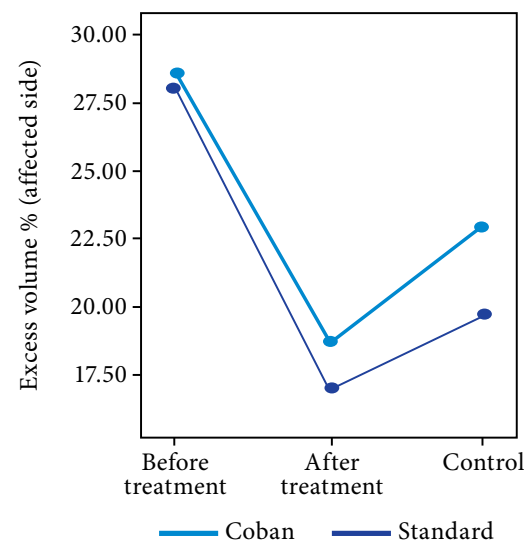

Figure 3. The changes in (a) volumes and (b) excess volumes recorded at baseline, after three weeks and at two months in conventional bandage (black line) and Coban ${ }^{\mathrm{TM}}$ bandage (grey line) groups.

\section{TABLE 4}

Ultrasonographic measurements of skin and subcutaneous thickness in affected extremities of both groups at prespecified time points

\begin{tabular}{|c|c|c|c|c|}
\hline & $\begin{array}{c}\text { Before treatment } \\
\text { Mean } \pm \text { SD }\end{array}$ & $\begin{array}{c}\text { After treatment } \\
\text { Mean } \pm \text { SD }\end{array}$ & $\frac{2^{\text {nd }} \text { month control }}{\text { Mean } \pm S D}$ & $\frac{\text { Intra-group }}{p}$ \\
\hline Skin thickness & & & & $1^{\mathrm{a}}$ \\
\hline Elbow point & & & & $0.585^{\mathrm{b}}$ \\
\hline Group 1 & $0.1 \pm 0.0$ & $0.1 \pm 0.0$ & $0.1 \pm 0.0$ & $0.1^{\mathrm{c}}$ \\
\hline Group 2 & $0.1 \pm 0.0$ & $0.1 \pm 0.0$ & $0.1 \pm 0.0$ & $1^{\mathrm{d}}$ \\
\hline $\mathrm{P}$ value between groups & 0.739 & 0.825 & 0.740 & $\begin{array}{l}0.715^{\mathrm{e}} \\
0.924^{\mathrm{f}}\end{array}$ \\
\hline Proximal & & & & $0.002^{\mathrm{a}}$ \\
\hline Group 1 & $0.2 \pm 0.1$ & $0.2 \pm 0.0$ & $0.2 \pm 0.0$ & $0.014^{\mathrm{b}}$ \\
\hline Group 2 & $0.2 \pm 0.1$ & $0.2 \pm 0.0$ & $0.2 \pm 0.0$ & $0.957^{c}$ \\
\hline $\mathrm{P}$ value between groups & 0.533 & 0.196 & 0.201 & $\begin{array}{l}0.016^{\mathrm{d}} \\
0.163^{\mathrm{e}} \\
0.522^{\mathrm{f}}\end{array}$ \\
\hline Distal & & & & $0.045^{\mathrm{a}}$ \\
\hline Group 1 & $0.2 \pm 0.0$ & $0.2 \pm 0.0$ & $0.2 \pm 0.0$ & $0.504^{\mathrm{b}}$ \\
\hline Group 2 & $0.2 \pm 0.1$ & $0.2 \pm 0.1$ & $0.2 \pm 0.1$ & $0.821^{\mathrm{c}}$ \\
\hline $\mathrm{P}$ value between groups & 0.904 & 0.824 & 0.899 & $\begin{array}{c}0.033^{\mathrm{d}} \\
1^{\mathrm{e}} \\
0.308^{\mathrm{f}}\end{array}$ \\
\hline Subcutaneous tissue thickness & & & & $0.002^{\mathrm{a}}$ \\
\hline Elbow point & & & & $0.000^{\mathrm{b}}$ \\
\hline Group 1 & $0.5 \pm 0.3$ & $0.4 \pm 0.2$ & $0.3 \pm 0.1$ & $0.158^{c}$ \\
\hline Group 2 & $0.5 \pm 0.2$ & $0.3 \pm 0.2$ & $0.3 \pm 0.2$ & $0.000^{\mathrm{d}}$ \\
\hline $\mathrm{P}$ value between groups & 0.506 & 0.791 & 0.828 & $\begin{array}{l}0.000^{\mathrm{e}} \\
0.256^{\mathrm{f}}\end{array}$ \\
\hline Proximal & & & & $0.000^{\mathrm{a}}$ \\
\hline Group 1 & $1.8 \pm 0.6$ & $1.4 \pm 0.6$ & $1.4 \pm 0.5$ & $0.000^{\mathrm{b}}$ \\
\hline Group 2 & $1.8 \pm 0.6$ & $1.4 \pm 0.5$ & $1.4 \pm 0.6$ & $1^{c}$ \\
\hline $\mathrm{P}$ value between groups & 0.997 & 0.983 & 0.654 & $\begin{array}{l}0.000^{\mathrm{d}} \\
0.000^{\mathrm{e}} \\
0.600^{\mathrm{f}}\end{array}$ \\
\hline Distal & & & & $0.000^{\mathrm{a}}$ \\
\hline Group 1 & $1.5 \pm 0.4$ & $1.3 \pm 0.4$ & $1.3 \pm 0.4$ & $0.007^{\mathrm{b}}$ \\
\hline Group 2 & $1.6 \pm 0.5$ & $1.2 \pm 0.4$ & $1.3 \pm 0.5$ & $0.520^{c}$ \\
\hline $\mathrm{P}$ value between groups & 0.498 & 0.966 & 0.795 & $\begin{array}{l}0.000^{\mathrm{d}} \\
0.000^{\mathrm{e}} \\
1^{\mathrm{f}}\end{array}$ \\
\hline
\end{tabular}




\section{TABLE 5}

Scores $(0-10)$ of the questions evaluating duration and easiness of applying bandages and comfortableness of bandages

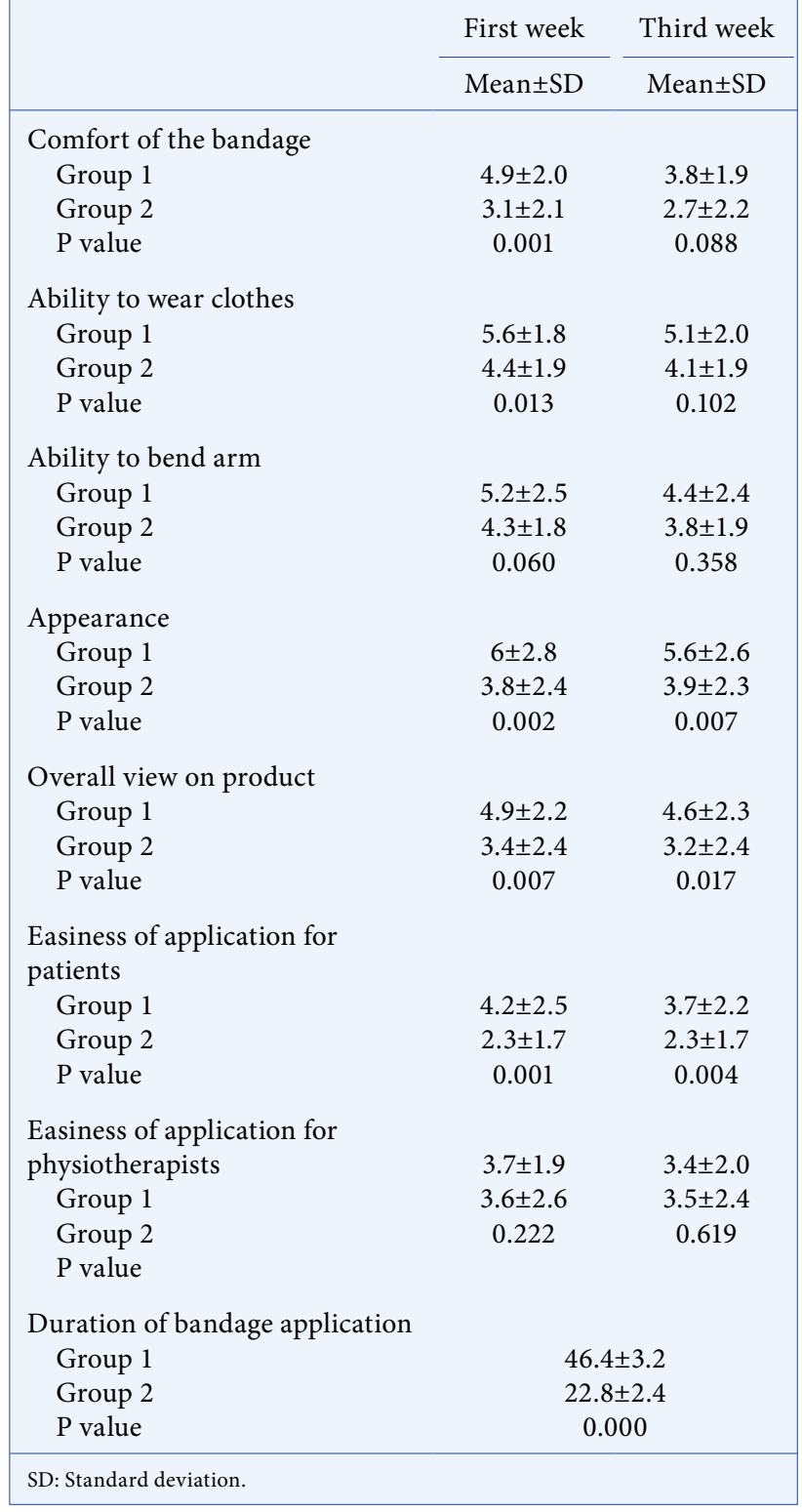

questionnaire are shown in Table 5. According to the phase 2 self-CDT treatment results, the patient compliance was found to be high in the majority of the patients in both groups and was statistically significantly similar between the groups $(p<0.05$, data not shown).

No serious or irreversible complications were observed during bandaging in either group. However, mild pruritis which responded to topical agents was reported in two patients in Group 1 and in one patient in Group 2.

\section{DISCUSSION}

Few studies have previously been performed to evaluate the comparative effectiveness of Coban ${ }^{\text {ix }}$ bandages with conventional ones. ${ }^{[9-11]}$ To the best of our knowledge, this is the first study to examine the comparative effectiveness of these different bandages in terms of different reliable outcome measures such as volume differences, functional and QoL scores, and ultrasonographic measurements in both short and long-term.

The efficacy and safety of Coban ${ }^{\text {Tx }} 2$ layer bandaging systems have been previously investigated in different patient groups with different application frequencies. The patient groups of previous comparative studies were relatively small and heterogeneous, and changes in volume were mostly calculated by the application of circumferential measurements or water displacement methods. ${ }^{[9-11]}$ Moffatt et al. ${ }^{[10]}$ demonstrated a high rate of volume reduction and good safety profile with the Coban ${ }^{\text {Tx }}$ bandages in short-term. A mean reduction of $18.7 \%$ in legs and $10.5 \%$ in arms were determined with the Coban ${ }^{\text {Tw }}$ bandages, while $10.9 \%$ and $8.2 \%$ volume reduction were observed in the traditional multi-layer short-stretch bandage in lower and upper extremities, respectively. Franks et al. ${ }^{[9]}$ investigated the performance of $3 \mathrm{M}^{\mathrm{Tm}}$ Coban $^{\text {tw }} 2$ layer bandages in 24 patients with upper and lower extremity lymphedema and concluded that all patients had significant reductions after threeweek treatment with the Coban ${ }^{\text {Tx }} 2$ layer bandages. Of note, the patients with lower extremity lymphedema experienced greater reductions in volume than those with upper extremity lymphedema with mean percentage changes of $14.9 \%$ and $16.1 \%$, respectively in limb volumes. In our study, both conventional and Coban $^{\text {tw }}$ treatment groups had comparable volume reductions ( $11 \%$ vs. $10 \%$, respectively) at the end of treatment. More importantly, at two months of follow-up, the reductions in the mean percentage volumes were sustained in both groups.

In recent years, ultrasonographic measurements have been gaining popularity in lymphedema studies. ${ }^{[17,18,30-34]}$ Although circumferential arm measurements are very common, these measurements cannot evaluate structural changes in subcutaneous tissue. ${ }^{[17,18,31,32]}$ There are few studies regarding the use of ultrasonographic measurement in assessing the response to CDT. ${ }^{[32-34]}$ Lee et al. $^{[32]}$ reported that the ultrasonographically determined mean soft tissue thickness significantly decreased after CDT in their patients with BCRL. Kim et al. ${ }^{[33]}$ also reported a 
higher reliability in the measurements of subcutaneous tissue and total soft tissue thickness than that of skin thickness measurement in 13 patients with BCRL. Sezgin Ozcan et al. ${ }^{[34]}$ observed a significant reduction in the subcutis thickness of 16 patients with BCRL after CDT and found a significant correlation between limb percentage change volume and ultrasonographic subcutis thickness measurements. Similar to previous studies, there were more significant improvements in the subcutaneous tissue thickness changes than in skin thickness changes in our study groups. The improvements in subcutaneous measurements at all points and improvements in proximal skin thickness were sustained at two months of follow-up in both groups.

Lymphedema may have severe consequences in terms of functional and psychosocial aspects of life of an individual. ${ }^{[35,36]}$ Specific tools for assessment of functional status in BCRL patients are still lacking in the literature. Therefore, we used the Q-DASH tool for functional disability, similar to previous studies. ${ }^{[5,37]}$ We determined significant improvements in the functional status in both study groups, which were sustained up to two months. However, accurate information on health-related QoL outcomes among patients with BCRL is needed to determine the effectiveness of treatments on the point of view of patients. Most of previous studies used generic questionnaires which are limited in reflecting specific symptoms and difficulties of the patients with lymphedema. ${ }^{[38]}$ In the current study, we used the LYMQOL-Arm questionnaire which is specifically developed for patients with upper extremity lymphedema. We observed a significant improvement in the QoL in terms of function, appearance, symptom, emotion, and general QoL in both study groups and all these improvements were sustained up to two months of follow-up.

The determination of comfortableness of different bandages by physiotherapists and patients' point of view is an important aspect. Morgan et al. ${ }^{[1]]}$ reported interviews from upper and lower lymphedema patients who previously used conventional multi-layer shortstretch bandages and, then, experienced Coban ${ }^{\text {ra }}$ 2 layer bandaging systems. Their patients' points of view indicated that the Coban ${ }^{\mathrm{Tu}}$ system was quicker and easier to apply which increased the extremity mobility and patient confidence and provided a sense of control and well-being. ${ }^{[1]}$ In another study, Moffatt et al. ${ }^{[10]}$ compared the duration of bandage application in conventional short-stretch bandaging versus Coban $^{\mathrm{Tm}}$ bandaging systems and reported significant shorter duration in the latter bandaging than the conventional treatment group. In our study, we used a questionnaire to obtain the patients' and physiotherapists' point of view about the bandages. Comfort of the bandage, ability to don-on/don-off, patient satisfaction with appearance, and overall scores of the product were significantly better in the Coban $^{\text {Tx }}$ bandage group than the conventional bandage group. In addition, bandage application time was approximately $46 \mathrm{~min}$ and $22 \mathrm{~min}$ in the conventional and Coban ${ }^{\text {tw }}$ bandaging groups, respectively, indicating the short-duration and easiness of application in the Coban ${ }^{\text {sx }}$ system. Although, in terms of costeffectiveness, the Coban ${ }^{\text {tx }}$ bandaging system seems to be more expensive than the traditional short-stretch bandages, it can be attributed as a cost-effective method when the application of the Coban ${ }^{\mathrm{Tx}}$ bandages twice a week, easiness of wearing clothes, and better functional capacities with less loss of working days are considered.

Nonetheless, there are also some limitations to this study. We were unable to assess the volumes with a more sensitive method such as a perometer or L-Dex bioimpedance spectroscopy; however previous studies indicated that circumferential measurements are in accordance with the perometer and/or L-Dex data in patients with BCRL. ${ }^{[39]}$ In addition, we strengthened our data with ultrasonographic measurements which can be a promising imaging tool for diagnosis and follow-up.

In conclusion, the Coban ${ }^{\mathrm{Tx}} 2$ layer bandaging performed as a part of CDT twice a week for a total of three weeks can reduce the volume and improve the functional disability and impaired QoL, similar to conventional short-stretch multi-layer bandages, both in the short- and long-term. Treatment with this layer system enables a time-efficient, easy, and comfortable application of bandaging with increased mobility of the upper extremity. We believe that the results of this study would contribute to planning of the lymphedema treatment in clinical practice and we suggest the use of Coban $^{\text {tw }} 2$ layer bandaging system as a part of CDT to perform an effective, time-efficient, and cost-effective treatment of BCRL.

\section{Declaration of conflicting interests}

The authors declared no conflicts of interest with respect to the authorship and/or publication of this article.

Funding

The authors received no financial support for the research and/or authorship of this article. 


\section{REFERENCES}

1. Tandra P, Kallam A, Krishnamurthy J. Identification and management of lymphedema in patients with breast cancer. J Oncol Pract 2019;15:255-62.

2. Michelotti A, Invernizzi M, Lopez G, Lorenzini D, Nesa F, De Sire A, et al. Tackling the diversity of breast cancer related lymphedema: Perspectives on diagnosis, risk assessment, and clinical management. Breast 2019;44:15-23.

3. Anbari AB, Wanchai A, Armer JM. Breast cancer-related lymphedema and quality of life: A qualitative analysis over years of survivorship. Chronic Illn 2019:1742395319872796.

4. Zuther JE, Norton S. Pathology. In: Zuther JE, Norton S, editors. Lymphedema Management: The Comprehensive Guide for Practitioners. 3rd ed. Sttuttgard: Thieme Verlag; 2013. p. 45-126.

5. Sezgin Ozcan D, Dalyan M, Unsal Delialioglu S, Duzlu U, Polat CS, Koseoglu BF. Complex decongestive therapy enhances upper limb functions in patients with breast cancerrelated lymphedema. Lymphat Res Biol 2018;16:446-52.

6. Lasinski BB, McKillip Thrift K, Squire D, Austin MK, Smith $\mathrm{KM}$, Wanchai A, et al. A systematic review of the evidence for complete decongestive therapy in the treatment of lymphedema from 2004 to 2011. PM R 2012;4:580-601.

7. Sayegh HE, Asdourian MS, Swaroop MN, Brunelle CL, Skolny MN, Salama L, et al. Diagnostic methods, risk factors, prevention, and management of breast cancerrelated lymphedema: past, present, and future directions. Curr Breast Cancer Rep 2017;9:111-21.

8. Executive Committee. The diagnosis and treatment of peripheral lymphedema: 2016 consensus document of the international society of lymphology. Lymphology 2016;49:170-84.

9. Franks PJ, Moffatt CJ, Murray S, Reddick M, Tilley A, Schreiber A. Evaluation of the performance of a new compression system in patients with lymphoedema. Int Wound J 2013;10:203-9.

10. Moffatt CJ, Franks PJ, Hardy D, Lewis M, Parker V, Feldman JL. A preliminary randomized controlled study to determine the application frequency of a new lymphoedema bandaging system. Br J Dermatol 2012;166:624-32.

11. Morgan PA, Murray S, Moffatt CJ, Young H. The experience of patients with lymphoedema undergoing a period of compression bandaging in the UK and Canada using the $3 \mathrm{M}^{\mathrm{mm}}$ Coban $^{\mathrm{TM}} 2$ compression system. Int Wound $\mathrm{J}$ 2011;8:586-98.

12. Schuren J, Bernatchez SF, Tucker J, Schnobrich E, Parks PJ. 3M Coban 2 Layer Compression Therapy: Intelligent Compression Dynamics to Suit Different Patient Needs. Adv Wound Care (New Rochelle) 2012;1:255-8.

13. International Society of Lymphology. The diagnosis and treatment of peripheral lymphedema: 2013 Consensus Document of the International Society of Lymphology. Lymphology 2013;46:1-11.

14. Blaney JM, McCollum G, Lorimer J, Bradley J, Kennedy R, Rankin JP. Prospective surveillance of breast cancer-related lymphoedema in the first-year post-surgery: feasibility and comparison of screening measures. Support Care Cancer 2015;23:1549-59.
15. Ancukiewicz M, Russell TA, Otoole J, Specht $M$, Singer M, Kelada A, et al. Standardized method for quantification of developing lymphedema in patients treated for breast cancer. Int J Radiat Oncol Biol Phys 2011;79:1436-43.

16. Karges JR, Mark BE, Stikeleather SJ, Worrell TW. Concurrent validity of upper-extremity volume estimates: comparison of calculated volume derived from girth measurements and water displacement volume. Phys Ther 2003;83:134-45.

17. Mellor RH, Bush NL, Stanton AW, Bamber JC, Levick JR, Mortimer PS. Dual-frequency ultrasound examination of skin and subcutis thickness in breast cancer-related lymphedema. Breast J 2004;10:496-503.

18. Jeon Y, Beom J, Ahn S, Bok SK. Ultrasonographic Evaluation of Breast Cancer-related Lymphedema. J Vis Exp 2017;119:54996.

19. Koldas Dogan S, Ay S, Evcik D, Baser O. Adaptation of Turkish version of the questionnaire Quick Disability of the Arm, Shoulder, and Hand (Quick DASH) in patients with carpal tunnel syndrome. Clin Rheumatol 2011;30:185-91.

20. Hudak PL, Amadio PC, Bombardier C. Development of an upper extremity outcome measure: the DASH (disabilities of the arm, shoulder and hand) [corrected]. The Upper Extremity Collaborative Group (UECG). Am J Ind Med 1996;29:602-8.

21. Borman P, Yaman A, Denizli M, Karahan S, Özdemir O. The reliability and validity of Lymphedema Quality of Life Questionnaire-Arm in Turkish patients with upper limb lymphedema related with breast cancer. Turk J Phys Med Rehabil 2018;64:205-12.

22. Keeley V, Crooks S, Locke J, Veigas D, Riches K, Hilliam R. A quality of life measure for limb lymphoedema (LYMQOL). Journal of Lymphoedema 2010;5:26-37.

23. Shao Y, Zhong DS. Manual lymphatic drainage for breast cancer-related lymphoedema. Eur J Cancer Care (Engl) 2017;26:e12517.

24. Zuther JE. Treatment sequences. Treatment. In: Zuther JE, Norton S, editors. Lymphedema Management. The Comprehensive guide for practitioners. 4 th ed. New York: Thieme; 2018. p. 311-2.

25. Zuther JE. Upper extremity bandaging. Application of compression bandages. In: Zuther JE, Norton S, editors. Lymphedema Management. The Comprehensive guide for practitioners. 4th ed. New York: Thieme; 2018. p. 408-12.

26. Available at: https://multimedia.3m.com/mws/ media/973854O/3m-coban-2-for-lymphoedema-poster-handand-arm-applications.pdf [Accessed: September 01, 2015]

27. Zhang L, Fan A, Yan J, He Y, Zhang H, Zhang H, et al. Combining manual lymph drainage with physical exercise after modified radical mastectomy effectively prevents upper limb lymphedema. Lymphat Res Biol 2016;14:104-8.

28. Brown JC, Cheville AL, Tchou JC, Harris SR, Schmitz $\mathrm{KH}$. Prescription and adherence to lymphedema selfcare modalities among women with breast cancer-related lymphedema. Support Care Cancer 2014;22:135-43.

29. Partsch H, Clark M, Mosti G, Steinlechner E, Schuren J, Abel M, et al. Classification of compression bandages: practical aspects. Dermatol Surg 2008;34:600-9. 
30. Mander A, Venosi S, Menegatti E, Byung-Boong L, Neuhardt $\mathrm{D}$, Maietti E, et al. Upper limb secondary lymphedema ultrasound mapping and characterization. Int Angiol 2019;38:334-42.

31. Hwang JH, Lee CH, Lee HH, Kim SY. A new soft tissue volume measurement strategy using ultrasonography. Lymphat Res Biol 2014;12:89-94.

32. Lee JH, Shin BW, Jeong HJ, Kim GC, Kim DK, Sim YJ. Ultrasonographic evaluation of therapeutic effects of complex decongestive therapy in breast cancer-related lymphedema. Ann Rehabil Med 2013;37:683-9.

33. Kim W, Chung SG, Kim TW, Seo KS. Measurement of soft tissue compliance with pressure using ultrasonography. Lymphology 2008;41:167-77.

34. Sezgin Ozcan D, Oken O, Dalyan Aras M, Koseoglu BF. Is Ultrasonography a Useful Method to Evaluate the Effectiveness of Complex Decongestive Therapy in Breast Cancer-related Lymphedema? Lymphology 2017;50:84-94.

35. Pinto M, Gimigliano F, Tatangelo F, Megna M, Izzo F, Gimigliano R, et al. Upper limb function and quality of life in breast cancer related lymphedema: a cross-sectional study. Eur J Phys Rehabil Med 2013;49:665-73.

36. O'Toole JA, Ferguson CM, Swaroop MN, Horick N, Skolny $\mathrm{MN}$, Brunelle $\mathrm{CL}$, et al. The impact of breast cancerrelated lymphedema on the ability to perform upper extremity activities of daily living. Breast Cancer Res Treat 2015;150:381-8.

37. Imamoğlu N, Karadibak D, Ergin G, Yavuzşen T. The Effect of Education on Upper Extremity Function in Patients with Lymphedema after Breast Cancer Treatments. Lymphat Res Biol 2016;14:142-7.

38. Cornelissen AJM, Kool M, Keuter XHA, Heuts EM, Piatkowski de Grzymala AA, van der Hulst RRWJ, et al. Quality of Life Questionnaires in Breast Cancer-Related Lymphedema Patients: Review of the Literature. Lymphat Res Biol 2018;16:134-9.

39. Coroneos CJ, Wong FC, DeSnyder SM, Shaitelman SF, Schaverien MV. Correlation of L-Dex Bioimpedance Spectroscopy with Limb Volume and Lymphatic Function in Lymphedema. Lymphat Res Biol 2019;17:301-7. 